\title{
Estimation of target strength of Sardina pilchardus and Sardinella aurita by theoretical approach
}

\author{
Salaheddine El Ayoubi' ${ }^{1 \cdot}$ Kamal Mamza $^{1} \cdot$ Tadanori Fujino $^{2,3} \cdot$ Koki Abe $^{4} \cdot$ Kazuo Amakasu $^{5}$ \\ Kazushi Miyashita ${ }^{6}$
}

\begin{abstract}
The target strength (TS) patterns of Sardina pilchardus and Sardinella aurita at 38 and $120 \mathrm{kHz}$ were estimated by a prolate-spheroid model, using measurements of swimbladder length and width. The ratio of swimbladder length to total length (TL) was similar in both species, however the ratio of swimbladder width to TL was smaller and more variable for S. aurita. Assuming a normal distribution of fish swimming orientation angle ( $\left(\theta\right.$ fish) with mean \pm standard deviation (SD) of $0 \pm 10^{\circ}$, the normalized (by TL) average TS $\left(b_{20}\right)$ was estimated to be $-64.0 \mathrm{~dB}(38 \mathrm{kHz})$ and $-65.2 \mathrm{~dB}(120 \mathrm{kHz})$ for S. pilchardus, and $-66.2 \mathrm{~dB}(38 \mathrm{kHz})$ and -67.2 $\mathrm{dB}(120 \mathrm{kHz})$ for $S$. aurita. Compared with currently applied $b_{20}$ values at $38 \mathrm{kHz}$, our results under four different $\theta_{\text {fish }}$ assumptions $\left(0 \pm 10^{\circ}, 0 \pm 15^{\circ},-5 \pm 10^{\circ}\right.$, and $\left.-5 \pm 15^{\circ}\right)$ were 6-9 dB higher for S. pilchardus and 5-7 $\mathrm{dB}$ higher for $S$. aurita. This suggests four- to eightfold overestimation risk for $S$. pilchardus and three- to fivefold overestimation risk for $S$. aurita when using the currently applied $b_{20}$ values.
\end{abstract}

Keywords Sardina pilchardus $\cdot$ Sardinella aurita $\cdot$ Target strength· Theoretical approach· Prolate spheroid model

Tadanori Fujino

tadanori@nagasaki-u.ac.jp

\footnotetext{
${ }^{1}$ Institut National de Recherche Halieutique, Lot ${ }^{\circ} 11$ nouveau port, Agadir 80010, Morocco

2 Marino Forum 21, 5F Hagoromo-building 1-5-2 Hatchobori Chuo-ku Tokyo 104-0032, Japan

${ }^{3}$ Present address: Center for International Collaborative Research, Nagasaki University, 1-12-4, Sakamoto, Nagasaki-shi, Nagasaki 852-8523, Japan

${ }^{4}$ National Research Institute of Fisheries Engineering, Fisheries Research Agency, 7620-7 Hasaki Kamisu-shi Ibaraki 314-0408, Japan

${ }^{5}$ Research Center for Advanced Science and Technology, Tokyo University of Marine Science and Technology, 4-5-7 Konan Minato-ku Tokyo 108-8477, Japan

${ }^{6}$ Field Science Center for Northern Biosphere, Hokkaido University, 20-5 Benten-cho, Hakodate-shi, Hokkaido 040-0051, Japan
} 


\section{Introduction}

Sardina pilchardus and Sardinella aurita are clupeoid species widely found in the eastern Atlantic Ocean, being important targets for purse seine fisheries [1,2]. S. pilchardus is found in the northeastern Atlantic, extending from the southern Celtic Sea and North Sea to Mauritania and Senegal, with residual populations also off The Azores, Madeira, and The Canary Islands [3]. S. aurita has a rather wide distribution, on both the eastern and western coast of the Atlantic Ocean [4]. Their catch is especially important in the northwest African region; over one million tons were landed annually from 2006 to 2010, dominating the small pelagic species catch in Morocco, Mauritania, and Senegal [1,2].

To assess the abundance of these two species, acoustic surveys have been carried out for nearly three decades by European and western African countries [1,2,5]. An acoustic survey collects the acoustic backscattering strength from fish schools, and converts it to density using target strength (TS), the intensity of sound backscattering from a single fish [6]. TS is known to be species specific and varies with several physical and biological factors such as fish swimming orientation angle, length, depth, carrier frequency, and physiology [6-9]. In general, swimming orientation angle is known to be the largest source of variation [6, 7], and the TS at a certain frequency under natural swimming orientation angle is expressed as a function of fish length $(L)$ in the form TS $=a \log L+b$, where $a$ is the slope and $b$ is the intercept. Assuming that the backscattering cross-section, which is the linear value of TS, is proportional to the square of fish length, TS $=20 \log L+b_{20}$ is applied in many species [6].

Regarding $S$. pilchardus, $b_{20}$ values ranging from -67.2 to $-66.4 \mathrm{~dB}$ were found by in situ TS measurements at $38 \mathrm{kHz}$ along the coast of Morocco [10]. This seems to be different from the lower $b_{20}$ value of $-70.5 \mathrm{~dB}$ found by in situ TS measurements at $38 \mathrm{kHz}$ for Sardinops ocellatus [11], a sardine species found off South Africa. Currently, European and African countries apply $b_{20}$ values ranging from -72.6 to $-70.5 \mathrm{~dB}$ for S. pilchardus [12], which mainly refers to values of Clupea harengus [13-15]. Similarly, a $b_{20}$ value of $-71.9 \mathrm{~dB}$ from $C$. harengus [15] is applied in Morocco for S. aurita, as species-specific TS knowledge is lacking. As a TS difference of several $\mathrm{dB}$ will result in a severalfold difference in abundance estimation (e.g., twofold for $3 \mathrm{~dB}$ ), reasonable species-specific TS- $L$ relationships should be applied for acoustic data analysis for both $S$. pilchardus and S. aurita.

In this study, we examined the TS of $S$. pilchardus and $S$. aurita by a theoretical approach using an acoustic backscattering model. Both species are physostomes [16, 17], i.e., fishes with an open swimbladder. The swimbladder represents $90-95 \%$ of the acoustic backscattering from the dorsal direction of the fish [18], so the TS for a fish can be considered to be close to the TS from the swimbladder. Several types of swimbladder backscattering models have been applied to estimate the TS from fish, including the Kirchhoff approximation (KA) model [19], Kirchhoff ray mode (KRM) model [20], deformed-cylinder model (DCM) [21], and prolate-spheroid model (PSM) [22]. Among these models, the KA, KRM, and DCM need detailed swimbladder shapes for their calculation, while the PSM approximates the swimbladder shape as a prolate spheroid and uses its major and minor axes for the calculation. In the present study, we could not obtain detailed swimbladder shapes, such as the stereoscopic structure of the swimbladder, as we relied on swimbladder measurements from the ventral-side visual of the swimbladder dimensions. As the application of KA, KRM, and DCM was difficult, 
we applied the PSM for TS estimation. By estimating the TS using the PSM under several swimming orientation angle assumptions, we intend to determine whether presently applied TS values [13-15] for S. pilchardus and $S$. aurita are reasonable, and indicate the potential TS difference between these two species.

\section{Materials and methods}

\section{Collection of fish samples and swimbladder observations}

Fresh fish samples of $S$. pilchardus $(N=45)$ and $S$. aurita $(N=64)$ were collected in the major purse seine fishing port at Agadir, Morocco. Shortly after landing of the fish, fresh samples in good condition were selected and their total length (TL) measured. The fish were then dissected from mouth to anus without damaging the swimbladder. After carefully removing the internal organs around the swimbladder, the length from the nose point to the head end of the swimbladder (swimbladder start length, SBS), swimbladder length (SBL), and swimbladder width (SBW) (see Fig. 1) were measured by digital caliper. Samples in which the swimbladder was damaged or had completely collapsed were excluded from the measurements.

For S. pilchardus, 13 additional live, anesthetized samples were also used to observe swimbladders adapted to surface water pressure and free from capture stresses. These samples were collected by a pelagic trawl (opening $\left.20 \times 30 \mathrm{~m}^{2}\right)$ of the R.V. Al Amir Moulay Abdallah (298 t), and were stored in a seawater circulating tank ( $1 \mathrm{~m}$ long $\times 1 \mathrm{~m}$ wide $\times 0.7 \mathrm{~m}$ deep) for over 2 weeks. Shortly before measurement, the fish were gently transferred to a solution of $1 \%$ 2-phenoxyethanol seawater for anesthetization and then measured in the same way as for the fresh samples (Fig. 1). Note that no obvious release of gas from the anal or pneumatic duct was observed during dissection or swimbladder measurements. Similarly, no obvious swimbladder dilation due to removal of the internal organs was observed.
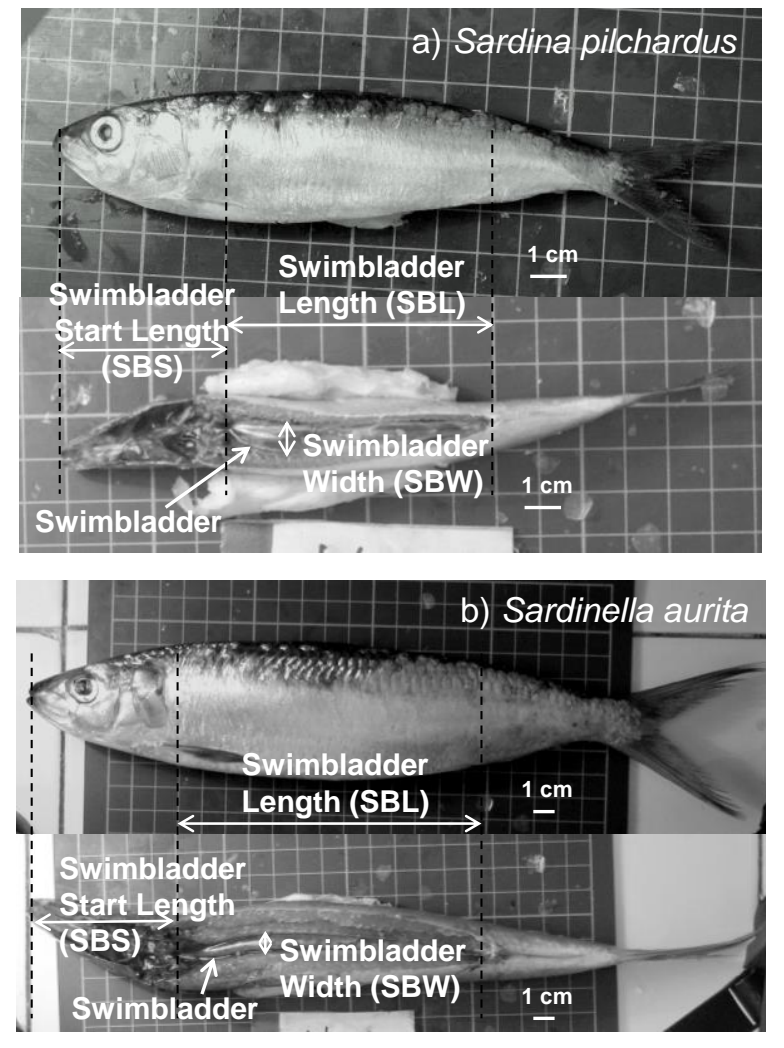

Fig. 1 Swimbladder measurements of a) S. pilchardus and b) S. aurita from the lateral side and dissected ventral side 


\section{Target strength estimation using a prolate spheroid model}

In the PSM, TS can be expressed as a function of $f, \theta_{\mathrm{sb}}, a, b$, and $c . f$ is the frequency, which was set 38 and 120 $\mathrm{kHz} . \theta_{\mathrm{sb}}$ is the swimbladder orientation angle $\left(-90^{\circ}\right.$, head down; $0^{\circ}$, horizontal; $90^{\circ}$, head up). $a$ and $b$ are the major and minor radii of the spheroid, respectively, being equal to half the SBL and SBW values obtained by the swimbladder measurements. $c$ is the speed of sound in the surrounding water and was set to $1500 \mathrm{~m} / \mathrm{s}$ in this study. TS was calculated for each $\theta_{\mathrm{sb}}$ value, but $\theta_{\mathrm{sb}}$ is not the same as the fish swimming orientation angle $\left(\theta_{\text {fish }}\right)$ because the swimbladder axis is not parallel to the body axis. Therefore, the swimbladder tilt angle $\theta_{\text {sb_tilt, which }}$

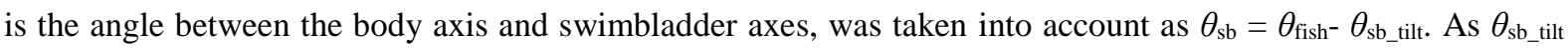
was difficult to measure by dissection, we assumed that $\theta_{\mathrm{sb} \_ \text {tilt }}$ was $6^{\circ}$ for $S$. pilchardus after Machias and Tsimenides [16] and $10^{\circ}$ for S. aurita after Whitehead and Blaxter [17]. After TS estimation for $\theta_{\text {fish }}$ from $-90^{\circ}$ to $90^{\circ}$ in $1^{\circ}$ steps, the average $\mathrm{TS}\left(\mathrm{TS}_{\mathrm{avg}}\right)$ under natural $\theta_{\text {fish }}$ was derived following the method of Foote [23], which assumes that $\theta_{\text {fish }}$ follows a normal distribution. Regarding daytime $\theta_{\text {fish }}$ of Clupeiformes, Ona [24] reported $-3.9 \pm 12.8^{\circ}$ and $0.2 \pm 11.9^{\circ}$ at different depth for C. harengus. Similarly, Amakasu et al. [25] referred $-3.7 \pm 8.6^{\circ}$, derived from observation of Engraulis japonicus. In this study, we considered a combination of average $0^{\circ}$ (horizontal) and $-5^{\circ}$ (slightly head down) with standard deviation set at $10^{\circ}$ and $15^{\circ}$, and assumed four patterns, namely $0 \pm 10^{\circ}, 0 \pm 15^{\circ},-5 \pm 10^{\circ}$, and $-5 \pm 15^{\circ}$, to estimate the daytime TS. Finally, after confirming the proportional growth of the swimbladder and body length, the $\mathrm{TS}_{\mathrm{avg}}$-TL relationship was fit using the following equation:

$\mathrm{TS}_{\mathrm{avg}}=20 \log \mathrm{TL}+b_{20}$,

where TL is total length $(\mathrm{cm})$ and $b_{20}$ is the normalized $\mathrm{TS}_{\mathrm{avg}}$ by length $(\mathrm{cm})$.

\section{Results}

\section{Swimbladder morphology}

Both S. pilchardus and S. aurita showed a smooth ellipsoidal-shaped swimbladder (Fig. 1). Table 1 presents the measured range of TL, the ratio of SBS to TL, the ratio of SBL to TL, and the ratio of SBW to SBL (aspect ratio). For $S$. pilchardus with TL in the range of $10-20 \mathrm{~cm}$ and $S$. aurita with TL in the range of 17-35 cm, the mean ratio of SBS to TL was identical (0.21). Similarly, the mean ratio of SBL to TL was identical (0.40) for both species, indicating that the relative position of the swimbladder to the fish body was the same in these two species. However, the aspect ratio for the two species was different, namely 0.09 for S. pilchardus and 0.07 for $S$. aurita, indicating narrower swimbladder shape for S. aurita compared with S. pilchardus.

Figure 2 shows the relationships between SBL and SBW versus TL for S. pilchardus and S. aurita, as well as Engraulis japonicus from Amakasu et al. [25] for comparison. Both SBL and SBW had positive correlation $(P \leq$ 0.001) with TL for S. pilchardus and S. aurita, indicating proportional development of the swimbladder with the fish body. The relationship between SBL and TL was similar in both species, showing crossover of the plots in the overlapping TL range (Fig. 2a, 17-20 cm). Compared with E. japonicus, the regression line for the two studied species was located higher, indicating a greater ratio of SBL to TL compared with E. japonicus. For S. pilchardus, crossover of the plots for the live and fresh samples was observed (Fig. 2a).

The relationship between SBW and TL differed between $S$. pilchardus and $S$. aurita, showing larger values for 
S. pilchardus in the overlapping TL range (Fig. 2b, 17-20 cm). For S. aurita, high variation was observed: for $S$. pilchardus, SBW values were not observed to overlap for TL differences of $10 \mathrm{~cm}$ (e.g., 10 to $20 \mathrm{~cm}$ ), whereas $S$. aurita showed overlapping SBW values for such differences (e.g., 20 to $30 \mathrm{~cm}$ ). The regression line for $E$. japonicus was located above the measurements for S. aurita but overlapped with the SBW of S. pilchardus. For S. pilchardus, crossover of the plots for the live and fresh samples was observed (Fig. 2b).

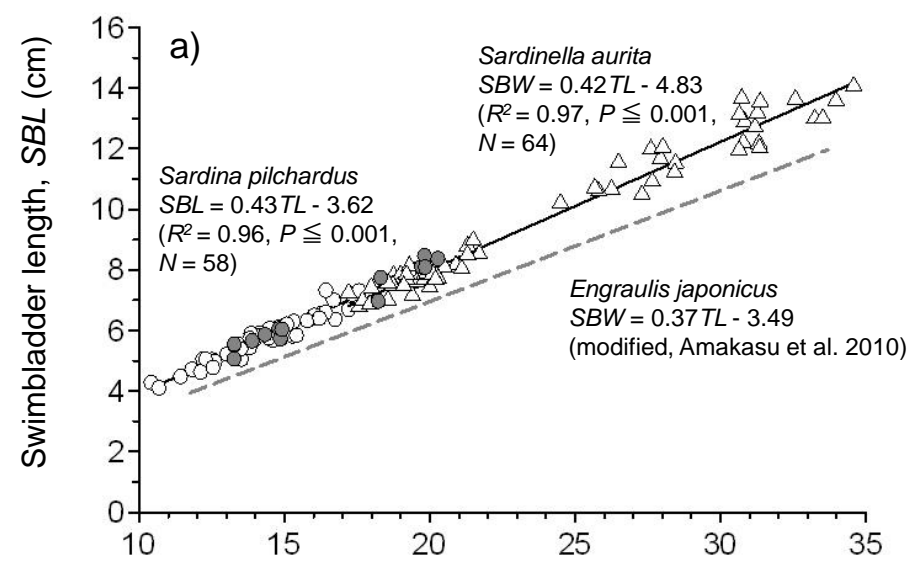

Fig. 2 a Relationship between TL and SBL for S. pilchardus and S. aurita. b Relationship between TL and SBW for $S$. pilchardus and $S$.

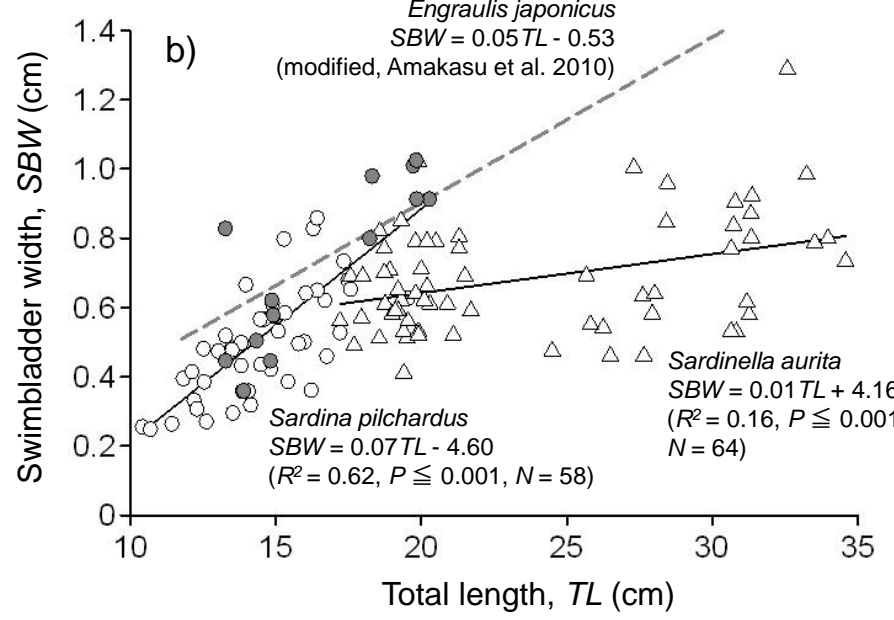
aurita. Unfilled circle indicates S. pilchardus measurements from fresh (dead) specimens; grey circle indicates $S$. pilchardus measurements from live, anesthetized specimens. Unfilled triangle indicates $S$. aurita measurements from dead specimens. Grey broken line indicates the relationship for $E$. japonicus modified from Amakasu et al. [25]

Table 1 Range of TL, ratio of SBS and SBL to TL, and ratio of SBW to SBL (aspect ratio) for S. pilchardus and S. aurita

\begin{tabular}{lccccc}
\hline Species & $N$ & TL $(\mathrm{cm})$ & SBS / TL & SBL / TL & SBW / SBL \\
\hline Sardina pilchardus & 58 & $10.4-20.3$ & $0.21 \pm 0.01(0.2-0.23)$ & $0.40 \pm 0.01(0.37-0.45)$ & $0.09 \pm 0.02(0.05-0.16)$ \\
Sardinella aurita & 64 & $17.2-34.6$ & $0.21 \pm 0.02(0.17-0.24)$ & $0.40 \pm 0.02(0.37-0.44)$ & $0.07 \pm 0.01(0.04-0.12)$ \\
\hline
\end{tabular}

\section{Target strength}

Figure 3 shows example relationships between TS and $\theta_{\text {fish }}$ (TS patterns), for three different swimbladder sizes at 38 and $120 \mathrm{kHz}$. The maximum TS values were similar or slightly higher at 120 compared with $38 \mathrm{kHz}$. The response of the TS to $\theta_{\text {fish }}$ was more sensitive at $120 \mathrm{kHz}$ compared with $38 \mathrm{kHz}$, showing a steep decrease from the maximum TS with varying $\theta_{\text {fish }}$.

Table 2 presents the $b_{20}$ values calculated for four different $\theta_{\text {fish }}$ distributions, namely normal distributions with 
mean $\pm \mathrm{SD}$ of $0 \pm 10^{\circ}, 0 \pm 15^{\circ},-5 \pm 10^{\circ}$ or $-5 \pm 15^{\circ}$. The $b_{20}$ values for $S$. pilchardus ranged from -65.0 to -63.5 $\mathrm{dB}$ at $38 \mathrm{kHz}$ and from -66.4 to $-64.6 \mathrm{~dB}$ at $120 \mathrm{kHz}$. For $S$. aurita, the $b_{20}$ values ranged from -66.8 to $-65.0 \mathrm{~dB}$ at $38 \mathrm{kHz}$ and from -67.9 to $-65.9 \mathrm{~dB}$ at $120 \mathrm{kHz}$. Among the four $\theta_{\text {fish }}$ distributions, $b_{20}$ was highest for mean \pm SD of $-5 \pm 10^{\circ}$, lowest for $0 \pm 15^{\circ}$, and intermediate for $0 \pm 10^{\circ}$. Comparing the two frequencies, $b_{20}$ was higher at 38 than $120 \mathrm{kHz}$, showing a 1.1-1.4 dB difference for $S$. pilchardus and 0.9-1.1 dB difference for $S$. aurita (Table 2), reflecting the different TS patterns in Fig. 3. Comparing the two species, $b_{20}$ for S. pilchardus was 1.4-2.2 dB higher than for $S$. aurita at $38 \mathrm{kHz}$ and $1.1-2.1 \mathrm{~dB}$ higher at $120 \mathrm{kHz}$.

Figure 4 shows the relationship between $\mathrm{TS}_{\text {avg }}$ and $\mathrm{TL}$ for $S$. pilchardus and $S$. aurita for a $\theta_{\text {fish }}$ distribution with mean $\pm \mathrm{SD}$ of $0 \pm 10^{\circ}$, together with that of E. japonicas for comparison (modified from Amakasu et al. [25]: scale length converted to TL). Among the three species, S. pilchardus had the highest $\mathrm{TS}_{\mathrm{avg}}$, E. japonicus was intermediate, and S. aurita was lowest at $38 \mathrm{kHz}$. At $120 \mathrm{kHz}$, S. pilchardus and E. japonicus showed similar $\mathrm{TS}_{\mathrm{avg}}$-TL relationships, while $S$. aurita had lower $\mathrm{TS}_{\mathrm{avg}}$ than $S$. pilchardus and E. japonicus.
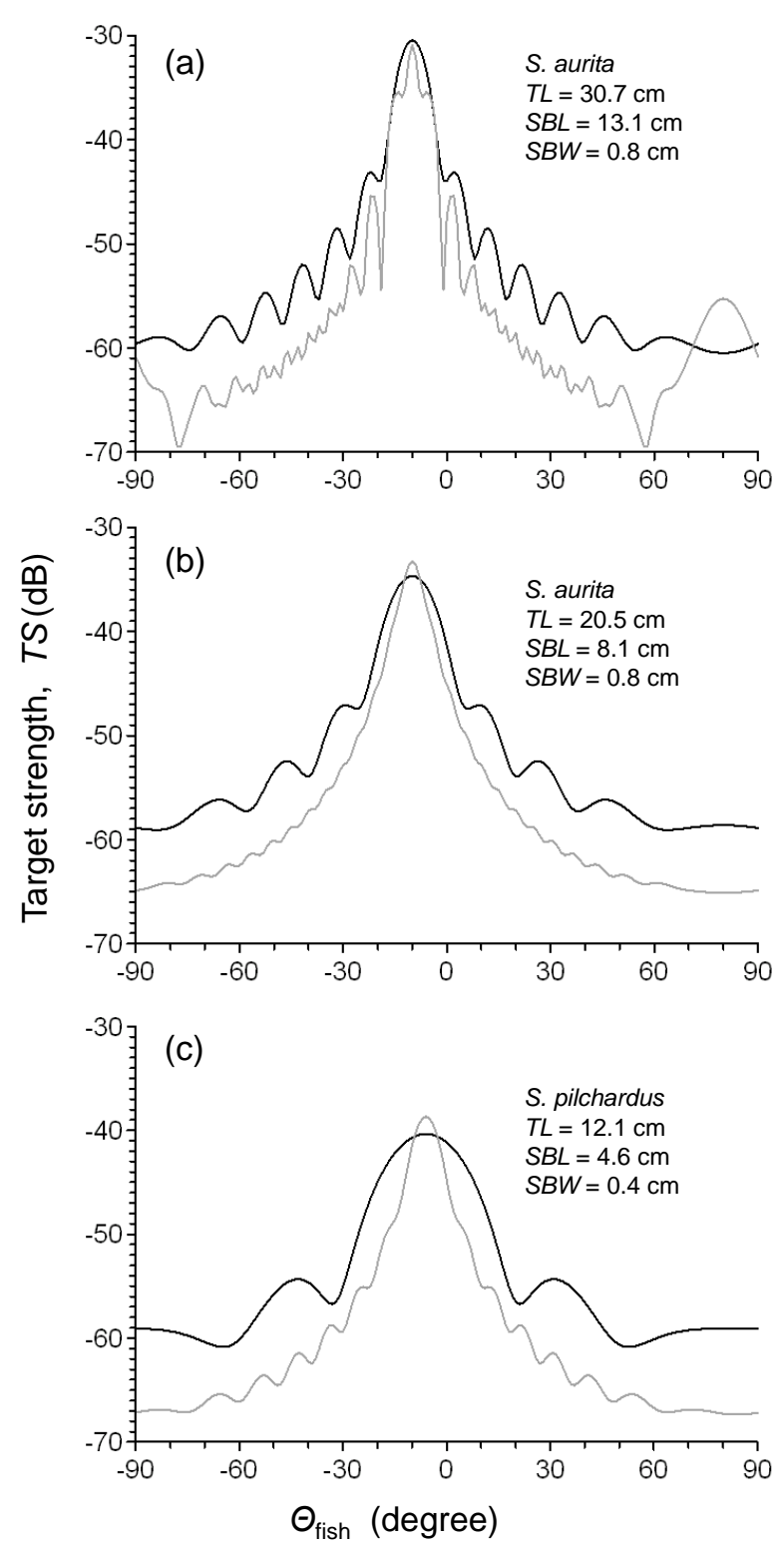

Fig. 3 Example relationships between TS and $\theta_{f i s h}$ at $38 \mathrm{kHz}$ (black line) and $120 \mathrm{kHz}$ (grey line) for: a $S$. aurita with $\mathrm{TL}=30.7 \mathrm{~cm}, \mathrm{SBL}=13.1 \mathrm{~cm}$, and $\mathrm{SBW}$ $=0.8 \mathrm{~cm} ; \mathbf{b}$ S. aurita with $\mathrm{TL}=20.5 \mathrm{~cm}, \mathrm{SBL}=8.1$ $\mathrm{cm}$, and $\mathrm{SBW}=0.8 \mathrm{~cm} ; \mathbf{c} S$. aurita with $\mathrm{TL}=12.1$ $\mathrm{cm}, \mathrm{SBL}=4.6 \mathrm{~cm}$, and $\mathrm{SBW}=0.4 \mathrm{~cm}$ 
Table 2 Normalized average TS $\left(b_{20}\right.$ of $\left.\mathrm{TS}_{\mathrm{avg}}=20 \log _{10} \mathrm{TL}+b_{20}\right)$ of $S$. pilchardus and $S$. aurita at four different fish swimming orientation angle $\left(\theta_{\text {fish }}\right)$ distributions

\begin{tabular}{lccccc}
\hline \multirow{2}{*}{ Distribution of $\theta_{\text {fish }}$} & \multicolumn{2}{c}{ Sardina pilchardus } & & \multicolumn{2}{c}{ Sardinella aurita } \\
\cline { 2 - 3 } \cline { 5 - 6 } (average, standard deviation) & $38 \mathrm{kHz}$ & $120 \mathrm{kHz}$ & & $38 \mathrm{kHz}$ & $120 \mathrm{kHz}$ \\
\hline$(0,10)$ & -64.0 & -65.2 & & -66.2 & -67.3 \\
$(0,15)$ & -65.0 & -66.4 & & -66.8 & -67.9 \\
$(-5,10)$ & -63.5 & -64.6 & & -65.0 & -65.9 \\
$(-5,15)$ & -64.8 & -66.1 & & -66.2 & -67.2 \\
\hline
\end{tabular}

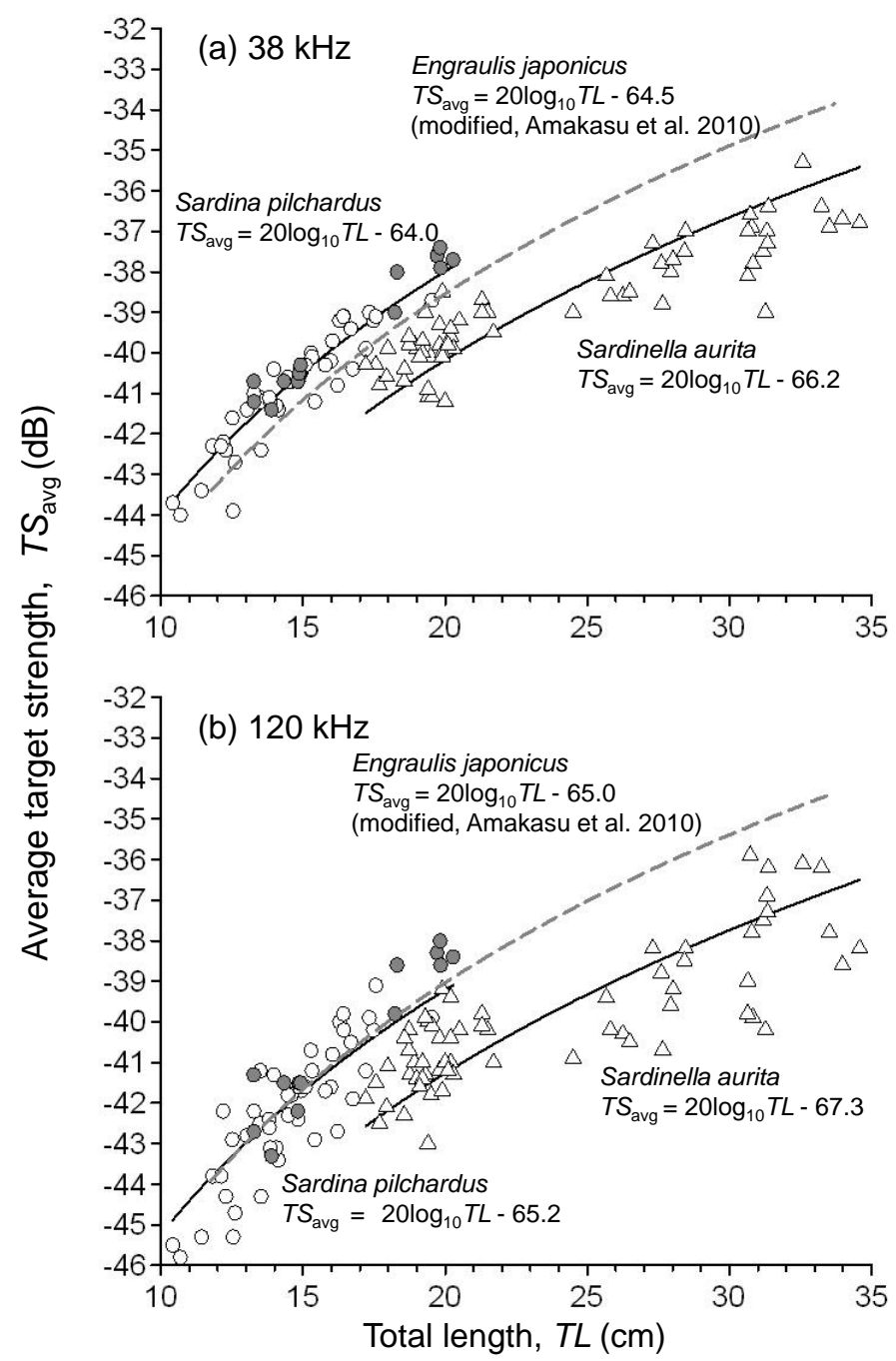

Fig. 4 Relationship between average TS (TS avg) and TL for S. pilchardus and S. aurita at a $38 \mathrm{kHz}$ and b $120 \mathrm{kHz}$. Unfilled circle indicates $S$. pilchardus TS estimated from dead specimens, grey circle indicates $S$. pilchardus TS estimated from live, anesthetized specimens. Unfilled triangle indicates $S$. aurita TS estimated from dead specimens. $\mathrm{TS}_{\text {avg }}$ values were calculated assuming a normal distribution of swimming tilt angle with average of $0^{\circ}$ and standard deviation of $10^{\circ}$. Grey broken line indicates the relationship for E. japonicus modified from Amakasu et al. [25]

\section{Discussion}

The results of the present study indicate $b_{20}$ values ranging from -65.0 to $-63.5 \mathrm{~dB}$ at $38 \mathrm{kHz}$ for S. pilchardus under four $\theta_{\text {fish }}$ distributions (Table 2). Compared with $b_{20}$ values reported for S. pilchardus off Morocco (-67.2 to $-66.4 \mathrm{~dB}[10])$ and currently applied $b_{20}$ values for $S$. pilchardus, using values from Clupea harengus (-72.6 to $-71.9 \mathrm{~dB}[13-15])$ or Sardinops ocellatus (-70.5 dB [11]), our results are rather close to the $b_{20}$ values for $S$. 
pilchardus obtained by in situ measurements off Morocco [10].

The $\mathrm{dB}$ difference between the $b_{20}$ values reported for $S$. pilchardus off Morocco and our result is 1.4-3.7 $\mathrm{dB}$. Possible reasons for the higher $b_{20}$ indicated in our study compared with the $b_{20}$ values obtained for $S$. pilchardus off Morocco could be the effect of $\theta_{\text {fish }}$ distributions, depth, and physiology. In the present study, we considered daytime $\theta_{\text {fish }}$ distributions and applied horizontal $\left(0^{\circ}\right)$ or slightly head-down $\left(-5^{\circ}\right)$ mean $\theta_{\text {fish }}$ with standard deviation of $10^{\circ}$ or $15^{\circ}$. However, the in situ measurements of $S$. pilchardus off Morocco were conducted at nighttime, meaning that $\theta_{\text {fish }}$ is likely to be different and have greater standard deviation compared with daytime [26-29]. A greater deviation in $\theta_{\text {fish }}$ results in a lower TS value (see Table 2), thus nighttime TS would be several dB lower compared with daytime [30-32]. For pelagic fish, Edwards and Armstrong [30] reported 2-3 dB lower TS at nighttime for caged herring. Similarly, Edwards and Armstrong [31] reported 4-5 $\mathrm{dB}$ lower TS for caged mackerel. This difference in diurnal $\theta_{\text {fish }}$ distributions seems to explain well the $\mathrm{dB}$ difference between our result and the nighttime $b_{20}$ values measured for S. pilchardus off Morocco [10].

Regarding depth and physiology, Ona reported that both affect the TS of C. harengus and described the effects via the following equation [9]:

$$
\text { TS }=20 \log L-2.3 \log \left(1+{ }^{z} / 10\right)-65.4+0.24(\mathrm{GSI})
$$

where $L$ is fish body length $(\mathrm{cm}), z$ is swimming depth $(\mathrm{m})$, and GSI is gonadosomatic index. In situ TS measurement of $S$. pilchardus off Morocco was conducted at a depth range of 10-35 $\mathrm{m}$ [10], hence it could give 0.7-1.5 dB higher $b_{20}$ values at the surface when applying Eq. (2). Considering that our sample had swimbladder condition close to that at the surface, based on the overlapping measurements for live and fresh samples (Fig. 2), this $0.7-1.5 \mathrm{~dB}$ difference could also explain our relatively high $b_{20}$ values. Regarding GSI, no information was obtained in the present study or in the report off Morocco [10], however studies on S. pilchardus showed GSI up to 6-6.6 [33, 34]. Applying Eq. (2), this would give a variation of up to $\pm 1.4-1.6 \mathrm{~dB}$. In summary, in situ TS measurements off Morocco ( $b_{20}$ of -67.2 to $-66.4 \mathrm{~dB}$ [10]) could be 2-3 dB higher at daytime compared with nighttime and the effect of depth could also give a 0.7-1.5 dB higher $b_{20}$ value at the surface. The effect of GSI is unknown but assumed to result in a variation of up to 1.4-1.6 dB. Given these factors, the 1.4-3.7 $\mathrm{dB}$ difference between our result and the nighttime $b_{20}$ values measured for S. pilchardus off Morocco [10] can be explained, indicating that our $b_{20}$ would be natural for $S$. pilchardus in daytime.

Our results seem more convincing in comparison with TS studies of E. japonicus, also a Clupeiformes physostome, which has a relationship between swimbladder size and TL that is not so different from $S$. pilchardus (Fig. 2). The nighttime in situ TS of E. japonicus is reported as $-68.3 \mathrm{~dB}\left(b_{20}, 12 \mathrm{~m}, 25 \mathrm{~m}\right.$ depth [35]) and $-67.6 \mathrm{~dB}\left(b_{20}, 10-45 \mathrm{~m}\right.$ depth [36]), which is close to the nighttime in situ TS of S. pilchardus $\left(b_{20},-67.2\right.$ to -66.4 dB, 10-35 m [10]). Daytime reports are 2-4 dB higher; a tank experiment using live E. japonicus specimens during daytime (confirmed to the author) showed $b_{20}$ of $-65.8 \mathrm{~dB}$ [37], and $b_{20}$ of $-64.5 \mathrm{~dB}$ was obtained using quick killed live samples with assumption of $\theta_{\text {fish }}$ distribution at $0 \pm 10^{\circ}$ (mean \pm SD) [25]. Considering the similar swimbladder size to $S$. pilchardus and the 2-4 $\mathrm{dB}$ difference in the $b_{20}$ values obtained for E. japonicus by nighttime in situ TS measurements and in daytime [25, 37], again our $b_{20}$ values for $S$. pilchardus (-65.0 to $-63.5 \mathrm{~dB})$ seem reasonable for daytime.

Regarding S. aurita, the TS would be rather low compared with S. pilchardus. The swimbladder of $S$. 
pilchardus and S. aurita had similar SBL and swimbladder start position (identical ratios of SBL to TL and SBS to TL), but the SBW of S. aurita showed greater variation and was smaller than for S. pilchardus (Table 1; Fig. 2). Smaller SBW was reflected in the TS estimation (Fig. 4; Table 2); the $b_{20}$ for $S$. aurita for each $\theta_{\text {fish }}$ distribution was 1.4-2.2 dB less at $38 \mathrm{kHz}$ and 1.1-2.1 dB less at $120 \mathrm{kHz}$ (Table 2) compared with S. pilchardus. This indicates that the TS of $S$. aurita could potentially be 1-2 dB lower compared with S. pilchardus.

In future work, more data on swimbladder tilt angle ( $\left.\theta_{\text {sb_titt }}\right)$ should be collected to verify the TS difference between $S$. pilchardus and $S$. aurita, as the present study applied this value from references [16, 17]. Observation methods such as soft X-rays [38] would enable more precise measurement of SBW and $\theta_{\text {sb_titt }}$ in the fish body, and provide the stereoscopic structure of the swimbladder, allowing application of theoretical models that take into account more details of the swimbladder structure [19-21]. Collection of tank-stored live S. aurita would be preferable, as the high variation in SBW (Fig. 2) could be due to either natural differences among individuals or the nature of the swimbladder, which is possibly fragile and more affected by the capture process compared with S. pilchardus. Meanwhile, considering the risk of overestimation by more than three- or fourfold if using the presently applied values (dB difference: S. pilchardus 6-9 dB, S. aurita 5-7 dB), revision of the TS value found in the present study (e.g., the $\theta_{\text {fish }} 0 \pm 10^{\circ}$ assumption) with the depth contraction parameter of Ona [9] should be applied for S. pilchardus and S. aurita.

Acknowledgements We thank the technicians of the Institut National de Recherche Halieutique (INRH) Agadir regional center for collection of fish samples in Agadir, Dr. Atsushi Kawabata for providing measurement data of E. japonicus, and the captain and crew of R.V. Al Amir Moulay Abdallah for keeping live S. pilchardus on board the vessel. The work was conducted under the Morocco-Japan cooperative project, "Capacity development of fisheries resource monitoring for the sustainable management of small pelagic resources in the Kingdom of Morocco" that involved cooperation between INRH and the Japan International Cooperation Agency (JICA). We are also grateful for the scientific support provided by Hokkaido University throughout the project.

\section{References}

1. FAO (2013) Report of the FAO Working Group on the Assessment of Small Pelagic Fish off Northwest Africa. Casablanca. Morocco, 24-28 May 2011. FAO Fisheries and Aquaculture Report No. 1026. Rome

2. FAO (2013) Report of the FAO Working Group on the Assessment of Small Pelagic Fish off Northwest Africa. Dakar, Senegal 21-25 May 2012. FAO Fisheries and Aquaculture Report No. 1036. Rome

3. Parrish RH, Serra R, Grant WS (1989) The monotypic sardines, Sardina and Sardinops: their taxonomy, distribution, stock structure, and zoogeography. Can J Fish Aquat Sci 46: 2019-2036

4. Bard FX, Koranteg KA (1995) Dynamics and use of sardinella resources from upwelling off Ghana and Ivory Coast. ORSTOM, Paris

5. ICES (2012) Report of the Working Group on Small Pelagic Fishes, their Ecosystems and Climate Impact (WGSPEC), 27 February - 2 March 2012, Fuengirola, Spain. ICES CM 2012/SSGEF: 10

6. Simmonds EJ, MacLennan DN (2005) Fisheries Acoustics: Theory and Practice. Blackwell Science, Oxford, United Kingdom 
7. Hazen EL, Horne JK (2003) A method for evaluating the effects of biological factors on fish target strength. ICES J Mar Sci, 60: 555-562

8. Ona E (1990) Physiological factors causing natural variations in acoustic target strength of fish. J Mar Biol Assoc UK, 70: 107-127

9. Ona E (2003) An expanded target strength relationship for herring. ICES J Mar Sci 60: 493-499

10. Svellingen I, Ona E (1999) A summary of target strength observations on fishes from the shelf off West Africa. Joint Meeting of ASA/EAA/DEGA. J Acoust Soc Am 105(2)

11. Barange M, Hampton I, Soule M. (1996) Empirical determination of in situ target strengths of three loosely aggregated pelagic fish species. ICES J Mar Sci 53: 225-232

12. ICES (2011) Report of the Working Group on Acoustic and Egg Surveys for Sardine and Anchovy in ICES Areas VIII and IX (WGACEGG), 22-26 November 2010, ICES CM 2010/SSGESST: 24

13. Degnbol P, Lassen H, Staehr KJ (1985) In-situ determination of target strength of herring and sprat at 38 and $120 \mathrm{kHz}$. Dana 5: 45-54

14. ICES (1982) Report of the 1982 Planning Group on ICES-Coordinated Herring and Sprat Acoustic Surveys. ICES Document CM 1982/H: 04

15. Foote KG (1987) Fish target strengths for use in echo integrator surveys. J Acoust Soc Am 82(3): 981-987

16. Machias A, Tsimenides N (1996) Anatomical and physiological factors affecting the swim-bladder cross-section of the sardine Sardina pilchardus. Can J Fish Aquat Sci 53: 280-287

17. Whitehead PJP, Blaxter JHS. (1989) Swimbladder form in clupeoid fishes. Zool J Linnean Soc 97: 299-372

18. Foote KG (1980) Importance of swimbladder in acoustic scattering by fish: A comparison of gadoid and mackerel target strengths. J Acoust Soc Am 67(6): 393-396

19. Foote KG (1985) Rather-high-frequency sound scattering by swimbladdered fish. J Acoust Soc Am 78: 688-700

20. Clay CS, Horne JK (1994) Acoustic models of fish : the Atlantic cod (Gadus morhua). J Acoust Soc Am, 96: 1661-1668

21. Ye Z, Furusawa M (1995) Modeling of target strength of swimbladder fish at high frequencies. J Acoust Soc Jpn 16: 371-379

22. Furusawa M (1988) Prolate spheroidal models for predicting general trends of fish target strength. J Acoust Soc Jpn 9: $13-24$

23. Foote KG (1980) Averaging of fish target strength functions. J Acoust Soc Am 67(2): 504-515

24. Ona E (1984) Tilt angle measurements on herring. ICES CM 1984/B: 19

25. Amakasu K, Sadayasu K, Abe K, Takao Y, Sawada K, Ishii K (2010) Swimbladder shape and relationship between target strength and body length of Japanese Anchovy (Engraulis japonicus). The Journal of the Marine Acoustics Society of Japan 37: 46-59 (in Japanese with English abstract and captions)

26. Beltestad AK (1973) Feeding behaviour and vertical migration in 0-group herring (Clupea harengus L.) in relation to light intensity. Candidata realium thesis, University of Bergen, Norway (in Norwegian)

27. Edwards JI, Armstrong F, Magurran AE, Pitcher TJ (1984) Herring, mackerel and sprat target strength experiments with behavioural observations. ICES CM 1984/B: 34

28. Foote KG, Ona E (1985) Tilt angles of schooling penned saithe. ICES CM 1985/B: 26 
29. Huse I, Ona E (1996) Tilt angle distribution and swimming speed of overwintering Norwegian spring-spawning herring. ICES J Mar Sci 53: 863-873

30. Edwards JI, Armstrong F (1983) Measurement of the target strength of live herring and mackerel. FAO Fish. Rep 300: 69-77

31. Edwards I, Armstrong F (1983) Target strength measurements on herring, sprat and mackerel. ICES CM 1983/B: 23

32. Traynor JJ, Williamson NJ (1983) Target strength measurements of walleye pollock (Theragra chalcogramma) and a simulation study of the dual beam method. FAO Fish Rep 300: 112-124.

33. Amenzoui K, Ferhan-Tachinante F, Yahyaoui A, Kifani S, Mesfioui AH (2006) Analysis of the cycle of reproduction of Sardina pilchardus (Walbaum, 1792) off the Moroccan Atlantic coast. C R Biol 329: 892-901

34. Pešić A, Đurović M, Joksimović A, Regner S, Simonović P, Glamuzina B (2010) Some reproductive patterns of the sardine, Sardina pilchardus (Walbaum, 1792), in Boka Kotorska Bay (Montenegro, southern Adriatic Sea) Acta Adriat 51(2): 159-168

35. Sawada K, Takahashi H, Abe K, Ichii T, Watanabe K, Takao Y (2009) Target-strength, length, and tilt-angle measurements of Pacific saury (Cololabis saria) and Japanese anchovy (Engraulis japonicus) using an acoustic-optical system, ICES J Mar Sci 66: 1212-1218

36. Zhao X, Wang Y, Dai F (2008) Depth-dependent target strength of anchovy (Engraulis japonicus) measured in situ. ICES J Mar Sci 65: 882-888.

37. Kang D, Cho S, Lee C, Myoung JG, Na J (2009) Ex situ target-strength measurements of Japanese anchovy (Engraulis japonicus) in the coastal Northwest Pacific. ICES J Mar Sci 66: 1219-1224

38. Sawada K, Ye Z, Kieser R, McFarlane GA, Miyanohana Y, Furusawa M (1999) Target strength measurements and modeling of walleye pollock and Pacific hake. Fish Sci 65: 193-205 